\title{
An innovative device for powders classification based on combined aerodynamic and electrostatic separation of particles
}

\author{
Bruno Piriou ${ }^{1}$, Claire Mayer-Laigle ${ }^{2}$, Firas Maalel ${ }^{2}$, Jorys Plissot ${ }^{2}$, and Xavier Rouau ${ }^{2, *}$ \\ ${ }^{1}$ CIRAD, unité de recherche Biomasse-Energie, TA-B 114/16, 34060 Montpellier cedex, France \\ ${ }^{2}$ INRA-CIRAD-University of Montpellier-Supagro Montpellier, unité mixte de recherches IATE, 34060 Montpellier cedex, France
}

\begin{abstract}
An innovative separator has been developed which aims at sorting out powders fractions according to aerodynamic and electrostatic properties of particles. The prototype is composed of a projection unit, a separation module and a classification/collection zone. The projection part is ensured by a pressurized gun. The separation module is conceived to disperse particles according to front and transverse directions. At the output of the gun, electrodes can be disposed to deviate the trajectory of charged particles. The classification part is made of a series of collecting bins. Starch, fine ash powders, and mixtures of these two materials were used to test the working of the separator. The efficiency of the separation was assessed by yields and particle sizes distribution of the collected fractions in the different bins. An aerodynamic classification was achieved along the main axis, with the finest particles crossing larger distances. With a blend of starch and ash, particles from both materials were unevenly distributed in the classifyier, opening the way to a possible separation based simply on aerodynamic properties. When an electric deviation was applied in addition to the projection of powders, the distribution of particles in the collecting part was modified.
\end{abstract}

\section{Introduction}

In the concept of biorefinery, fractionation of lignocellulosic biomass is a prerequesite for further valorization into energy, chemicals or synthons, and materials [1]. Dry processing, that yields intermediate powdered products, is particularly attractive as it has low environmental impact with no water and solvent consumption nor generation of other effluents [2]. Dry fractionation includes a step of dissociation, generally obtained by grinding and milling, and a step of separation or classification which allows the sorting out of distinct fractions. Several techniques of classification can be used, taking advantage of different properties of the powder components: sieving based on particle sizes, aerodynamic sorting based on particle densities and shapes, and electrostatic sorting based on chemical compositions of particles. These techniques are usually employed separately but may be considered jointly to increase the resolution of the separation process [3]. In the present work we have developed an innovative separator which aims at sorting out mixtures of lignocellulosic powders according to the aerodynamic and electrostatic properties of individual particles. The device has been sized following the potential performances of a pressurized machine designed for plasma spraying of ceramic fine powders, in using corn starch and rice husk ash as references. The separative efficiency of the device was assessed with a mix of these two powdered materials.

\section{Materials and methods}

\subsection{Description of the equipment}

The prototype is composed of a projection unit, a separation module and a classification/collection zone (Figure 1). The projection part is ensured by a pressurized gun controlled to expel powders at fixed flow rates (Sulzer Metco 9MP-CL20, Oerlikon). The powder is fluidized in a vibrating feed hopper then directed to a pressurized channel and projected throuh a diffuser designed to deliver a ribbon-like shaped blast (dimensions of the diffuser: $0.051 \mathrm{~m}$ height, $0.003 \mathrm{~m}$ width, $0.00015 \mathrm{~m}^{2}$ section). The air flow was set at $15-18 \mathrm{l} / \mathrm{mn}$ to maintain the powder flow rate at $20 \mathrm{~g} / \mathrm{mn}$. In these conditions, the maximum front distance of projection was approximately $1 \mathrm{~m}$ for all tested powders. The lateral extent of the deposit was approximately $0.4 \mathrm{~m}$. The separation module is 
composed of a plexiglass housing allowing powders to disperse through the diffuser according to front and transverse directions. This module has $1.2 \mathrm{~m}$ length and $0.5 \mathrm{~m}$ width. Preliminary experiments have shown that part of the particles stuck onto the walls of the housing. Therefore, the walls were covered inside with an earthed wire mesh to avoid unwanted electrostatic phenomenon. At the output of the diffuser, two electrodes of $25 \mathrm{~cm}$ length and $5 \mathrm{~cm}$ height connected to a high voltage generator $(0-20 \mathrm{kV})$ can be disposed to create an electrical field able to deviate the trajectory of particles which have been triboelectrically charged by rubbing in the projecting part of the gun. The classification part is made of a series of 18 collecting bins $(25 \times 10 \mathrm{~cm})$ covering the whole separation area and allowing to distinguish fractions deposited according to the main projection axis and also right and left sides (9 bins on the right, 9 bins on the left). Powders fractions collected in the different bins were weighted separately in order to determine their distribution and their median particle sizes $\left(d_{50}\right)$ were measured with a laser granulometer (Mastersizer 2000, Malvern, France).

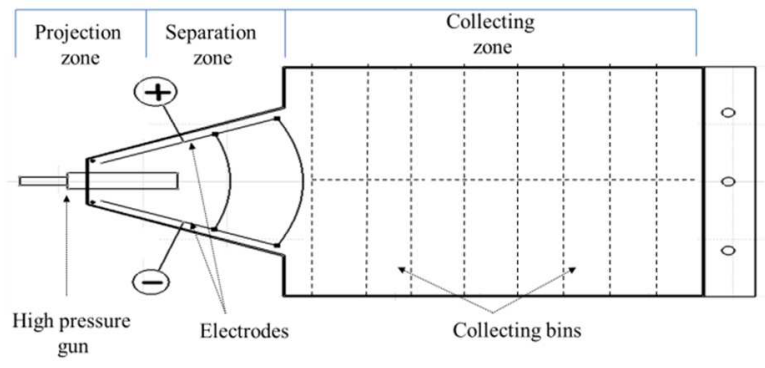

Fig. 1. Top view scheme of the separator

\subsection{Powder samples}

The maize starch powder (Maizena, Unilever, France) had an average particle size (d50) of $20 \mu \mathrm{m}$ and a true density of 1.2. The ash was obtained from full calcination $\left(900^{\circ} \mathrm{C}\right.$, $3 \mathrm{~h}$ ) of rice husk (silo de Tourtoulen, Arles, France). It exhibited a $\mathrm{d}_{50}$ of $27 \mu \mathrm{m}$ and a true density of $\sim 2$. The ratio of starch and ash masses recovered in the bins after separation was assessed by the measurement of mineral contents of the powder blends in weighting residual ash after calcination in a furnace at $900^{\circ} \mathrm{C}$ during $2 \mathrm{~h}$, assuming a mineral content of $0 \%$ for starch and $100 \%$ for ash.

\subsection{Regime of the projection flow}

Calculations were made to determine the Reynolds number in different air velocity conditions, using the following relations:

$$
\begin{aligned}
& \text { v_p = v_air }=\text { D_air } / \mathrm{S} * 60 \\
& v=\mu \_ \text {air } / \rho \_ \text {air } \\
& \mathrm{R}=\left(\mathrm{v} \_ \text {air*l }\right) / v
\end{aligned}
$$

with v_p et v_air as particles and air velocities, respectively $(\mathrm{m} / \mathrm{s})$, D as air flow rate $\left(\mathrm{m}^{3} / \mathrm{min}\right), \mathrm{S}$ as diffuser cross section $\left(\mathrm{m}^{2}\right), \mathrm{v}$ as kinematic viscosity $(1.46$ E-05 $\left.\mathrm{m}^{2} / \mathrm{s}\right), \mu$ as air dynamic viscosity $(1.79 \mathrm{E}-05 \mathrm{~kg} / \mathrm{m} / \mathrm{s})$, rho as air volumic mass $\left(1.22 \mathrm{~kg} / \mathrm{m}^{3}\right), \mathrm{R}$ as the Reynolds number

\section{Results and discussion}

\subsection{Laminarity of the powder flows}

The powders used in the experiments had mean particle sizes around $20 \mu \mathrm{m}$. It was necessary to maintain a laminar flow to allow constant speed of the particles and a consequent good control of the forces applied to the powder flow. The flow can be considered as laminar if the Reynolds number is below 2000. Then, their speed at the diffuser outlet was considered identical to the air flow Results obtained with different air flow rates are reported in Table 1.

Table 1. Air velocity, Reynolds numbers and flow regimes obtained for increasing air flow rates at the exit of the diffuser (temperature: $288 \mathrm{~K}$ ).

\begin{tabular}{cccc}
\hline $\begin{array}{c}\text { Air flow } \\
\text { rate } \\
\left(\mathrm{m}^{3} / \mathrm{min}\right)\end{array}$ & $\begin{array}{c}\text { Air } \\
\text { velocity } \\
(\mathrm{m} / \mathrm{s})\end{array}$ & Reynolds number & Régime \\
\hline 0.010 & 1.09 & 223 & Laminar \\
0.011 & 1.20 & 246 & Laminar \\
0.012 & 1.31 & 268 & Laminar \\
0.013 & 1.42 & 290 & Laminar \\
0.014 & 1.53 & 312 & Laminar \\
0.015 & 1.63 & 335 & Laminar \\
0.016 & 1.74 & 357 & Laminar \\
\hline
\end{tabular}

Therefore, the regime of particle flows was laminar whatever the air flow rate in the range used in these experiments.

\subsection{Aerodymanic experiments}

$200 \mathrm{~g}$ starch and ash powders were separately applied to the separator to test the behaviour of the fine particles. A typical separation curve is shown in Figure 2, with ash powder as an example. Fractions of the powder were collected in the bins according to the distance from the diffuser, and their granulometry was measured. It was observed that the main part of the material was recovered at distance comprised between 10 and $30 \mathrm{~cm}$ from their starting point. These particles had a median particle size of $\sim 20 \mu \mathrm{m}$ corresponding to the powder nominal $\mathrm{d}_{50}$. For longer distances, decreasing amounts of powder fractions 
with regularly decreasing particle sizes were collected. This distribution is in accordance with the particle size distribution curve of this powder obtained from laser granulometry. Interestingly, a small-sized particle fraction was recovered at a very short distance from the diffuser. This results probably from turbulent flowing at the exit of the diffuser and the formation of eddied which attracts small particles at first place. A similar curve was obtained with starch powder, with a slight shift towards larger distances of recovery.

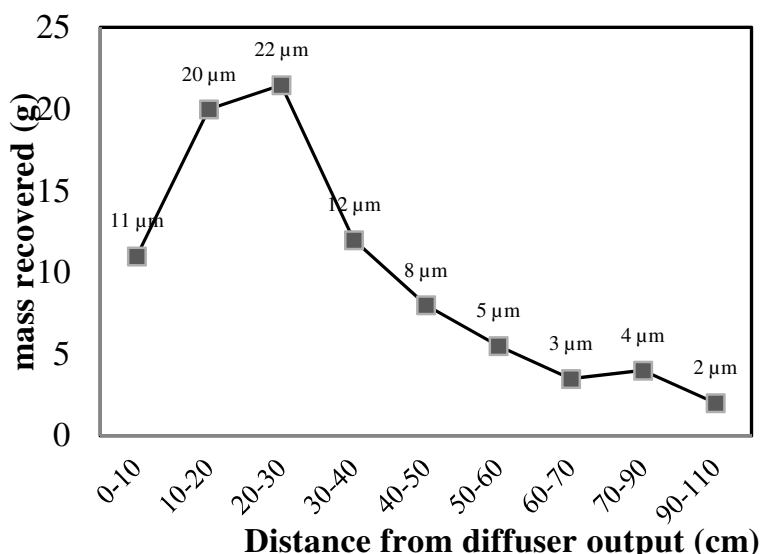

Fig. 2. Mass distribution and median particle sizes (d50) of ash powder particles as a function of the distance from diffuser exit (powder flow rate: $20 \mathrm{~g} / \mathrm{min}$, air flow rate: $18 \mathrm{l} / \mathrm{min}$ ).

A 50/50 blend of starch and ash was then separated in the device with the same operating conditions. The result is shown in Figure 3. The $10-40 \mathrm{~cm}$ zone from the diffuser was clearly enriched in ash particles, whereas starch particles were more concentrated in the more distant zone $(50-110 \mathrm{~cm})$. In the shortest zone $(0-10 \mathrm{~cm})$, approximately equal amounts of starch and ash were present. This distribution evidences that the behaviour of particles is different in blends compared to monocomponent powders. Here it is seen that the denser ashrich fractions repel the lighter starch-rich fractions to longer distances of recovery. This opens the way to a partial separation of the two components in a simple manner.

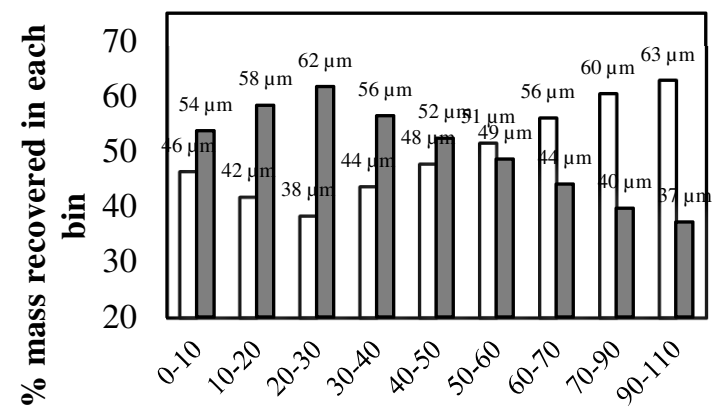

Distance from diffuser output $(\mathrm{cm})$

Fig. 3. Mass ratio distribution of starch (white) and ash (grey) from a 50/50 blend separation according to the projection distance from the exit of diffuser (powder flow rate: $20 \mathrm{~g} / \mathrm{min}$, air flow rate: $18 \mathrm{l} / \mathrm{min}$ )

\subsection{Electrostatic experiments}

Preliminary experiments combining pressurized projection and electric deviation of powders have been carried out. Both starch and ash powders were used separately for these experiments. When a $10 \mathrm{kV}$ tension was applied between the electrodes, it was observed that the powder clouds were deviated as compared to purely aerodynamic tests and that part of the particles were going to stick onto the charged electrodes. These first results already demonstrate the interest of coupling dynamic aero- and electro-separations, but must be completed by further experiments that are currently under realization. These experiments use mixtures of starch and ash powders and will be interpreted by comparing to the separation obtained by the aerodynamic set up alone.

\section{Conclusion}

A prototype innovative device for the classification of complex fine powders of lignocellulosic biomass was designed. The instrument included elements for the projection, the classification and the collection of fine particles. It was dimensioned following experiments carried out with pure starch and ash powders. Mixtures of these two powders were used to assess the separation performances of the equipment. With simple projection of powders, a partial classification of the mixture was obtained so that fractions enriched in starch or in ash could be collected. The coupling with an electric deviation of the tribo-electrically charged particles was also set up, additionnal separative phenomena were observed, in preliminary experiments. These results point out a possible new mode of recovering partially purified fractions from complex and heterogeneous vegetal powders. When the different geometries and conditions of use will be finalized, the prototype equipment would be ready for scale-up development for a potential usage in plant biomass bio-refinery.

\section{References}

1. V. Menon, M. Rao, Trends in bioconversion of lignocellulose: Biofuels, platform chemicals \&amp; biorefinery concept, Prog. Energy Combust. Sci., 38,522550 (2012)

2. A. Barakat, H. de Vries, X. Rouau, Dry fractionation process as an important step in current and future lignocellulose biorefineries: A review, Bioresour. Technol., 134, 362-373 (2013)

3. M.A.I. Schutyser and A.J. van der Goot, The potential of dry fractionation processes for sustainable plant protein production. Trends Food Sci. Technol., 22, 154-164 (2011) 